\title{
Isobaric tags for relative and absolute quantitation-based proteomics analysis of the effect of ginger oil on bisphenol A-induced breast cancer cell proliferation
}

\author{
DAN LEI ${ }^{1 *}$, TAO HONG ${ }^{2 *}$, LONGXUE LI $^{1}$, LAI CHEN $^{1}$, \\ XIAOQUAN LUO ${ }^{1}$, QINGHUA WU ${ }^{3}$ and ZHIYONG LIU ${ }^{1,4}$ \\ ${ }^{1}$ Experimental Animal Center, ${ }^{2}$ School of Clinical Medicine, ${ }^{3}$ Basic Medical College, Jiangxi University \\ of Traditional Chinese Medicine; ${ }^{4}$ Key Laboratory of Pharmacology of Traditional Chinese Medicine in \\ Jiangxi, Jiangxi University of Traditional Chinese Medicine, Nanchang, Jiangxi 330004, P.R. China
}

Received May 6, 2020; Accepted October 27, 2020

DOI: $10.3892 / \mathrm{ol} .2020 .12362$

\begin{abstract}
Several chemicals in the environment, particularly those with estrogenic activity and small amounts (micromolar or lower) of environmental estrogen can cause changes in cell function and interfere with endocrine functions of animals and humans. These compounds enter the human body and increase the load of estrogen in the body, leading to an
\end{abstract}

Correspondence to: Dr Zhiyong Liu, Experimental Animal Center, Jiangxi University of Traditional Chinese Medicine, 1688 Meiling Street, Nanchang, Jiangxi 330004, P.R. China

E-mail: liuzhiyong0791@163.com

Ms. Qinghua Wu, Basic Medical College, Jiangxi University of Traditional Chinese Medicine, 1688 Meiling Street, Nanchang, Jiangxi 330004, P.R. China

E-mail: 53266506@qq.com

${ }^{*}$ Contributed equally

Abbreviations: iTRAQ, isobaric tags for relative and absolute quantitation; GEO, ginger essential oil; BPA, bisphenol A; GEO-BPA, ginger essential oil and bisphenol A; COX2, cytochrome c oxidase subunit 2; TEAB, triethylammonium bicarbonate buffer; TCEP, tris (2-carboxyethyl) phosphine; LC, liquid chromatography; MS, mass spectrometry; DMSO, dimethylsulfoxide; TAM, tamoxifen; NDUFA8, NADH dehydrogenase (ubiquinone) 1 alpha subcomplex subunit 8; NDUFS4, NADH dehydrogenase (ubiquinone) iron-sulfur protein 4, mitochondrial; ND2, NADH-ubiquinone oxidoreductase chain 2; SDHB, succinate dehydrogenase (ubiquinone) iron-sulfur subunit, mitochondrial; SDHC, succinate dehydrogenase cy tochrome b560 subunit, mitochondrial; SOD2, superoxide dismutase (Mn), mitochondrial; SNRPE, small nuclear ribonucleoprotein E; MRPL13, 39S ribosomal protein L13, mitochondrial; ROS, 39S ribosomal protein L13, mitochondrial; OXPHOS, oxidative phosphorylation; GO, Gene Ontology; KEGG, Kyoto Encyclopedia of Genes and Genomes

Key words: iTRAQ, oxidative phosphorylation; breast cancer, ginger increasing incidence of estrogen-related tumors in breast cancer, ovarian cancer and endometrial cancer. Previous studies have demonstrated that ginger can inhibit the expression of estrogen receptors, while the bioactive ingredients of ginger sig-nificantly inhibit proliferation and promote the apoptosis of breast cancer cells. In the present study, a quantitative proteomics technique based on relative and absolute quanti-tative isobaric labeling was used to determine the effect of ginger essential oil (GEO) and BPA combined treatment on the proteomic characteristics of MCF-7 cells. In total, 5,084 proteins were detected. Proteins that were upregulated $>1.2$-fold and downregu-lated by $>0.8$-fold were differentially expressed. Overall, 528 differentially expressed proteins were identified. Compared with the control group, MCF-7 cells treated with GEO, BPA and GEO-BPA resulted in 45 (14 up- and 31 downregulated), 481 (141 up- and 340 downregulated) and 34 (13 up- and 21 downregulated) differentially ex-pressed proteins, respectively. Compared with the BPA group, MCF- 7 cells treated with GEO-BPA resulted in 210 (117 up- and 93 downregulated ) differentially expressed proteins, among the 210 differentially expressed proteins in the GEO-BPA group, 10 proteins were associated with oxidative phosphorylation pathways, while succinate dehydrogenase (ubiquinone) iron-sulfur subunit (SDHB), succinate dehydrogenase cytochrome b560 subunit, mitochondrial (SDHC), cytochrome $c$ oxidase subunit 2 and superoxide dismutase (Mn), mitochondrial (SOD2) expression was decreased with GEO-BPA combined treatment. Through the analysis of Gene Ontology and Kyoto Encyclopedia of Genes and Genomes, the cellular localization, func-tional annotation and biological pathways of differentially expressed proteins were ex-amined. The results indicated that GEO-BPA may act through the oxidative phosphory-lation pathway, decreased the expression of SDHB and SDHC, affected the tricarbox-ylic acid cycle and decreased the expression of SOD2. This may have led to oxidative stress and the death of breast cancer cells, and the SDH signaling pathway may be an important mediator of the inhibitory effects of GEO in MCF-7 breast cancer cells. GEO can inhibit the proliferation of breast cancer MCF-7 cells induced by BPA, and the underlying mechanism may be 
associated with oxidative phosphorylation. These results may aid the development of future treatment strategies for breast cancer caused by environmental estrogen exposure.

\section{Introduction}

Breast cancer is one of the most common malignant tumors among females. According to statistics in 2018, 9.57 million individuals died of cancer worldwide, of which $\sim 627,000$ died from breast cancer (1). However, the current prevention and treatment methods need to be improved. Clinical, epidemiological and biological studies have indicated that exogenous estrogen is associated with the occurrence and development of breast cancer (2). Bisphenol A (BPA) is an exogenous estrogen, which is one of the most widely used industrial compounds in human daily life. BPA is similar to estrogen in structure and has stable chemical properties. It is widely used in plastic products, food containers, beverage bottles and dental fillings materials (3). When heated in mi-crowave ovens, plastic residues, such as bisphenol A may penetrate into the food (4). BPA is difficult to metabolise and excrete, thus interfering with the endocrine system of the human body (5). In previous years, a large number of experiments have confirmed that BPA can interfere with the normal functions of the human reproductive, nervous and immune systems and embryonic development. In addition, BPA promotes the occurrence and development of various tumors, such as breast and prostate cancer and children's reproductive system tumors (6,7). Liu et al (8) reported that bisphenol can regulate the expression of EMT-related protein markers by promoting the expression of Snail, thereby enhancing the migration ability of breast cancer MCF-7 cells.

Ginger (Zingiber officinale) is the fresh rhizome of ginger, a perennial herb of the Zingiberaceae family. Ginger is a traditional Chinese medicine that is used for both food and medicine (9). Previous studies have reported that ginger serves an antitumor role in various types of malignant tumors (10-17). For example, 6-gingerol, the main active component of ginger, can induce the apoptosis of gastric cancer cells via different mechanisms (11). (6)-gingerol can effectively inhibit colon tumor growth in nude mice (12) and (6)-paradol has antitumor-promoting properties (13). Ginger extract can inhibit growth and induce apoptosis in prostate cancer models in vivo and in vitro (14). Volatile ginger oil has strong cytotoxicity in cervical cancer cells (15) and treatment of gastroin-testinal tumors (16). Karki has demonstrated that ginger oil inhibits hallmarks [cyclin D1, cyclin dependent kinase (Cdk)-2, Cdk-4 and Bcl-2] of breast cancer cells (17). The purpose of the present study was to investigate the function of ginger essential oil (GEO) on breast cancer cells induced by bisphenol A, and provide an experimental and theoretical basis of potential therapeutic targets and the development of novel drugs.

MCF-7, a widely studied epithelial cancer cell line derived from breast adenocarcinoma, has characteristics of differentiated mammary epithelium (18). In the present study, relative and absolute quantitative isobaric labeling (iTRAQ) technology was for comprehensive proteomic analysis of MCF-7 cells, which were treated with single or a therapeutic trace estrogen combination (BSA). In addition, bioinformatics and function-al analysis, including Gene Ontology (GO), Kyoto Encyclopedia of Genes and Genomes (KEGG), cluster analysis and protein-protein interaction (PPI) network analysis, were used. The present study may provide an experimental basis to improve our under-standing of the underlying molecular mechanisms of GEO-induced apoptosis in breast cancer cells.

\section{Materials and methods}

Cell culture. The human breast cancer cell line MCF-7 was obtained from Fuheng Bio-logical Company (https://www.fudancell.com). Cell culture was completed at the Laboratory Animal Science and Technology Center of Jiangxi University of Traditional Chinese Medicine. MCF-7 cells were cultured in MEM medium (Solibao, China, http://www.solarbio.com) with $10 \%$ fetal bovine serum (FBS; Serana Europe) and 1\% penicillin-streptomycin (Solibao, China) and incubated in a humid $\mathrm{CO}_{2}$ incubator at $37^{\circ} \mathrm{C}$. MCF-7 is an estrogen receptor breast cancer cell line (18).

Preparation of GEO. In total, $500 \mathrm{~g}$ fresh ginger was crushed, put into a 5,000-ml round-bottom flask, mixed with $3,000 \mathrm{ml}$ distilled water, heated and refluxed in a heating hood for $6 \mathrm{~h}$. The volatile oil was extracted using $n$-hexane and dried over anhydrous sodium sulfate. Weight the ginger oil and stored at $4^{\circ} \mathrm{C}$. Additionally, $200 \mathrm{mg} / 1$ was determined as the optimal concentration of ginger essential oil to treat MCF-7 cells through cytotoxicity tests (19).

Cell treatment. BPA was purchased from Macklin Inc., and dissolved with DMSO (Solibao, China, http://www.solarbio. com) solution. MCF-7 cells were plated at $1 \times 10^{6}$ cells per well in a 6-well plate. Then MCF-7 cells were incubated for $24 \mathrm{~h}$ at $37^{\circ} \mathrm{C}$ to allow adhesion, and then the minimum Eagle's medium (MEM; Hyclone, Cytiva) was removed and new media with GEO $(25,50,100,150,200$ and $250 \mathrm{mg} / \mathrm{l})$ or BPA $\left(10^{-5}, 10^{-6}\right.$, $10^{-7}, 10^{-8}$ and $10^{-9} \mathrm{~mol} / \mathrm{l}$ ) or GEO-BPA (GEO $200 \mathrm{mg} / \mathrm{l}$, BPA $10^{-5}, 10^{-6}, 10^{-7}, 10^{-8}$ and $10^{-9} \mathrm{~mol} / \mathrm{l}$ ) at the different concentrations were added, MCF-7 cells were again incubated at $37^{\circ} \mathrm{C}$ in a $5 \% \mathrm{CO}_{2}$ incubator. After $48 \mathrm{~h}$, the cells were collected for further analysis. All experiments were performed in triplicate.

Cell viability analysis. Cell viability was determined using an MTT assay. MCF-7 cells were inoculated in a 96-well plate with $1 \times 10^{4}$ cells per well. The cells were incubated at $37^{\circ} \mathrm{C}$ for $24 \mathrm{~h}$ to allow them to adhere to the bottom of the plate, then MEM was removed and new media of GEO $(25,50$, $100,150,200$ and $250 \mathrm{mg} / \mathrm{l})$ or BPA $\left(10^{-5}, 10^{-6}, 10^{-7}, 10^{-8}\right.$ and $10^{-9} \mathrm{~mol} / \mathrm{l}$ ) or GEO-BPA (GEO $200 \mathrm{mg} / \mathrm{l}$, BPA $10^{-5}, 10^{-6}, 10^{-7}$, $10^{-8}$, and $10^{-9} \mathrm{~mol} / \mathrm{l}$ ) at the different concentrations were added. After reaching the treatment time (24, 48 or $72 \mathrm{~h}), 20 \mu \mathrm{l}$ of $5 \mathrm{mg} / \mathrm{ml} \mathrm{MTT}$ was added to each well. The cells were incubated in a $5 \% \mathrm{CO}_{2}$ incubator at $37^{\circ} \mathrm{C}$ for $4 \mathrm{~h}$. The medium was then removed and MTT was dissolved with $150 \mu \mathrm{l}$ DMSO solvent per well. The cells were stirred in the dark for $15 \mathrm{~min}$ on a shaking table at $75 \mathrm{rpm}$, and then the absorbance was measured at $490 \mathrm{~nm}$ us-ing spectrophotometry.

Protein extraction. An appropriate amount (10-15 $\mu \mathrm{l})$ of cell sample was treated with liquid nitrogen, then protein lysate (8 M urea $+1 \%$ SDS, including protease inhibitor cocktail (Thermo Fisher Scientific, Inc.) at a ratio of 1:5 was added. Cells were centri-fuged at $16,000 \mathrm{xg}$ at $4^{\circ} \mathrm{C}$ for $30 \mathrm{~min}$ to 
collect the supernatant and 5x volume of pre-cooled acetone was added and precipitated overnight at $-20^{\circ} \mathrm{C}$. The next day the supernatant was centrifuged at $12,000 \mathrm{x}$ g at $4^{\circ} \mathrm{C}$ for $30 \mathrm{~min}$ and the precipitate was collected. The precipitate was washed with $90 \%$ pre-cooled acetone and air dried. The precipitate was then dissolved it with $200 \mu \mathrm{l}$ of protein lysate $(8 \mathrm{M}$ urea $+1 \% \mathrm{SDS}$, with cocktail) and finally centrifuged at $12,000 \mathrm{x} \mathrm{g}$ at $4^{\circ} \mathrm{C}$ for $30 \mathrm{~min}$ to collect the protein supernatant.

$S D S-P A G E$. The protein sample $(20 \mu \mathrm{g})$ was mixed with a $5 \mathrm{X}$ loading buffer and boiled for $5 \mathrm{~min}$. Then the SDS-PAGE was performed on a $12.5 \%(\mathrm{v} / \mathrm{w})$ polyacrylamide gel for quantification. Biologically repeated in triplicate.

Reductive alkylation and enzymatic hydrolysis. Triethylammonium bicarbonate buffer (TEAB) $(1 \mathrm{~mol} / \mathrm{l})$ was added to a $100-\mu \mathrm{g}$ protein sample of different treatment groups to make a TEAB final concentration $100 \mathrm{mM}$ in tubes. Then tris (2-carboxyethyl) phosphine (TCEP) was added to each tube to make a final TCEP concentration of $100 \mathrm{mM}$, and reacted at $37^{\circ} \mathrm{C}$ for $60 \mathrm{~min}$. After, iodoacetamide was added to each tube to make a final concentration of $40 \mathrm{mM}$. The reaction solution was incubated at room temperature in the dark for $40 \mathrm{~min}$, then pre-cooled acetone (acetone: sample $\mathrm{v} / \mathrm{v}=6: 1$ ) was added to each tube. The solution was precipitated at $-20^{\circ} \mathrm{C}$ for $4 \mathrm{~h}$, then centrifuged at $10,000 \mathrm{xg}$ for $20 \mathrm{~min}$ at $4^{\circ} \mathrm{C}$. The precipitate was collected and fully dissolved with $100 \mu \mathrm{l}$ of $100 \mathrm{mM}$ TEAB. Trypsin was then added according to the enzyme: protein $(\mathrm{m} / \mathrm{m})=1: 50$, and incubated at $37^{\circ} \mathrm{C}$ overnight.

iTRAQ labeling. The samples were digested with trypsin, the peptides were dried using a vacuum pump, and reconstituted with $0.5 \mathrm{M}$ TEAB. According to the manufacturer's instructions, peptides $(\sim 100 \mu \mathrm{g})$ in each group were labeled using the iTRAQ Labeling kit (cat. no. 4390812; Shanghai AB SCIEX Analytical Instrument Trading Co.).

High pH ultra high-performance liquid chromatography (UPLC) first dimension separation. The peptide samples $(100 \mathrm{mM} / \mathrm{l})$ of $\mathrm{MCF}-7$ cells in different treatment groups were reconstituted with UPLC loading buffer [2\% acetonitrile (adjusted to $\mathrm{pH} 10.0$ with ammonia)], and a high $\mathrm{pH}$ liquid phase separation was performed with a reverse phase ACQUITY UPLC BEH C18 column $(1.7 \mu \mathrm{m}, 2.1 \mathrm{~mm}$ $\mathrm{X}$ 150; Waters Coporation) us-ing the Vanquish Flex Binary UHPLC system (Thermo Fisher Scientific, Inc.). Mobile phase A: $2 \%$ Acetonitrile (adjusted to $\mathrm{pH} 10.0$ with ammonia), Mobile phase B: $80 \%$ Acetonitrile (adjusted to $\mathrm{pH} 10.0$ with ammonia). The ultraviolet detection wavelength was $214 \mathrm{~nm}$. The flow rate was $200 \mu \mathrm{l} / \mathrm{min}$ and the gradient was $47 \mathrm{~min}$.

High-performance liquid chromatography-mass spectrometry (HPLC-MS). Samples were analyzed using HPLC-MS in positive and negative ion mode, a reverse phase C18 column (75 $\mu \mathrm{m} \times 25 \mathrm{~cm})$ and an Easy-1200 chromatography instrument (both Thermo Fisher Scientific, Inc.). The MS instrument was Q_Exactive HF-X (Thermo Fisher Scientific, Inc.) and chromatographic separation time was $120 \mathrm{~min}$. Mobile phase A: $2 \%$ Acetonitrile $0.1 \%$ formic acid and B: $80 \%$ acetonitrile $0.1 \%$ formic acid. The flow rate was $300 \mathrm{nl} / \mathrm{min}$, and the MS scanning range $(\mathrm{m} / \mathrm{z})$ was $350-1,300$. Nitrogen gas tem-perature was $35^{\circ} \mathrm{C}$ and nebulizer pressure was 5500 psi.

Proteomics data analysis. The original MS data were extracted from the original files. These files were submitted to the Proteome discoverer server (https://www.thermofisher. com/order/catalog/product/OPTON-30810\#/OPTON-30810) and the NCBInr database (https://www.ncbi.nlm.nih.gov) was searched.

Bioinformatics analysis. For proteins obtained by MS, proteins that were upregulated by $>1$.2-fold, downregulated by $>0.8$-fold and $\mathrm{P}<0.05$ were considered to be differentially expressed $(20,21)$. Cluster version 3.0 was used for hierarchical cluster analysis, and the cellular components and molecules of the different proteins were analyzed by BLAST2GO version 2.5.0 (https://www. blast2go.com), KOBAS version 2.1.1 (http://kobas.cbi.pku.edu. cn) and Goa tools version 0.6.5 (https://www.ebi.ac.uk/GOA). The functional and biological processes were classified by clustering, and the differences in protein functions were discussed based on annotation information. The gene symbols obtained from the target protein sequence database were used to study the target protein and experimental evidence using Cytoscape version 3.7.2 and the STRING database (https://string-db.org/) for network analysis of protein-protein interactions (PPIs) (22).

Statistical analysis. For one-variable experiments, P-values were calculated using the paired Student's t-test, while P-values from two-variable experiments were calculated using the two-way ANOVA and Dunnett's multiple comparisons test. Data are expressed as mean \pm standard deviation and mean \pm SEs of three independent biological replicates. $\mathrm{P}<0.05$ was considered to indicate a statistically significant difference.

\section{Results}

Cell viability. As shown in Fig. 1, when the treatment time was constant, the viability MCF-7 cells decreased with increasing GEO concentration. This was most notable when the treatment concentration was $250 \mathrm{mg} / \mathrm{l}$ at all treatment durations. When the GEO concentration was constant, the viability of MCF-7 cells decreased with the prolongation of the treatment time, and reached the lowest at $72 \mathrm{~h}$. Compared with the control group, BPA improved cell viability and the cell viability reached its maximum when the BPA concentration was $10^{-7} \mathrm{~mol} / \mathrm{l}$. Meanwhile, following GEO-BPA treatment, the cell viability decreased compared with the BPA group. In short, GEO inhibited the proliferation of breast cancer MCF-7 cells, while BPA promoted this; however, GEO overcame BPA-induced promotion of proliferation.

$L C-M S / M S$. The present study used iTRAQ technology to analyze the proteomic characteristics of MCF-7 cells, which were treated with different concentrations of GEO or BPA alone or GEO mixed with BPA. The experimental procedure is shown in Fig. 2. Overall, a total of 5,084 proteins were detected (Table SI). The quality control of protein data showed that the molecular mass of the protein was in the range of 0-100 kDa (Fig. 3A), and the length of most peptides were between 7 and 17 amino acids (Fig. 3B), which is similar to the properties of known trypsin peptides (23). 


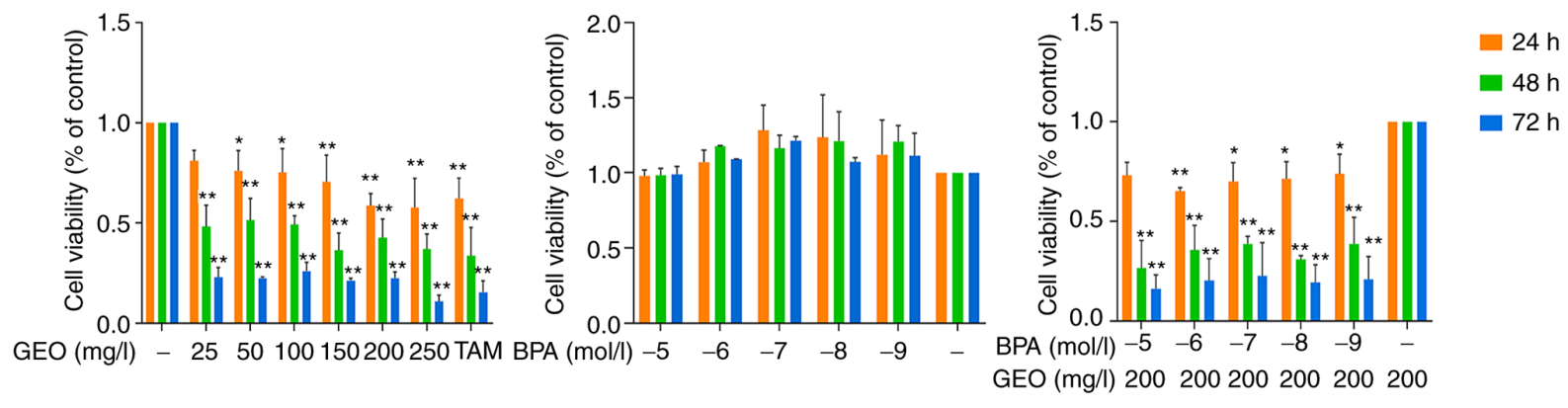

Figure 1. Effect of GEO, BPA, GEO-BPA on the viability of MCF-7 cells. MCF-7 cells were incubated with different concentrations of GEO (0-250 mg/l), BPA $\left(10^{-5}-10^{-9} \mathrm{~mol} / \mathrm{l}\right)$ and GEO $(200 \mathrm{mg} / \mathrm{l})$-BPA $\left(10^{-5}-10^{-9} \mathrm{~mol} / \mathrm{l}\right)$ and the cell viability was measured at different time points. The results are plotted as the means \pm SEs $(n=3)$ of the percent-age of viable cells relative to the control. ${ }^{*} \mathrm{P}<0.05$ and ${ }^{* *} \mathrm{P}<0.01$ vs. control group. GEO, ginger essential oil; BPA, bisphenol A.

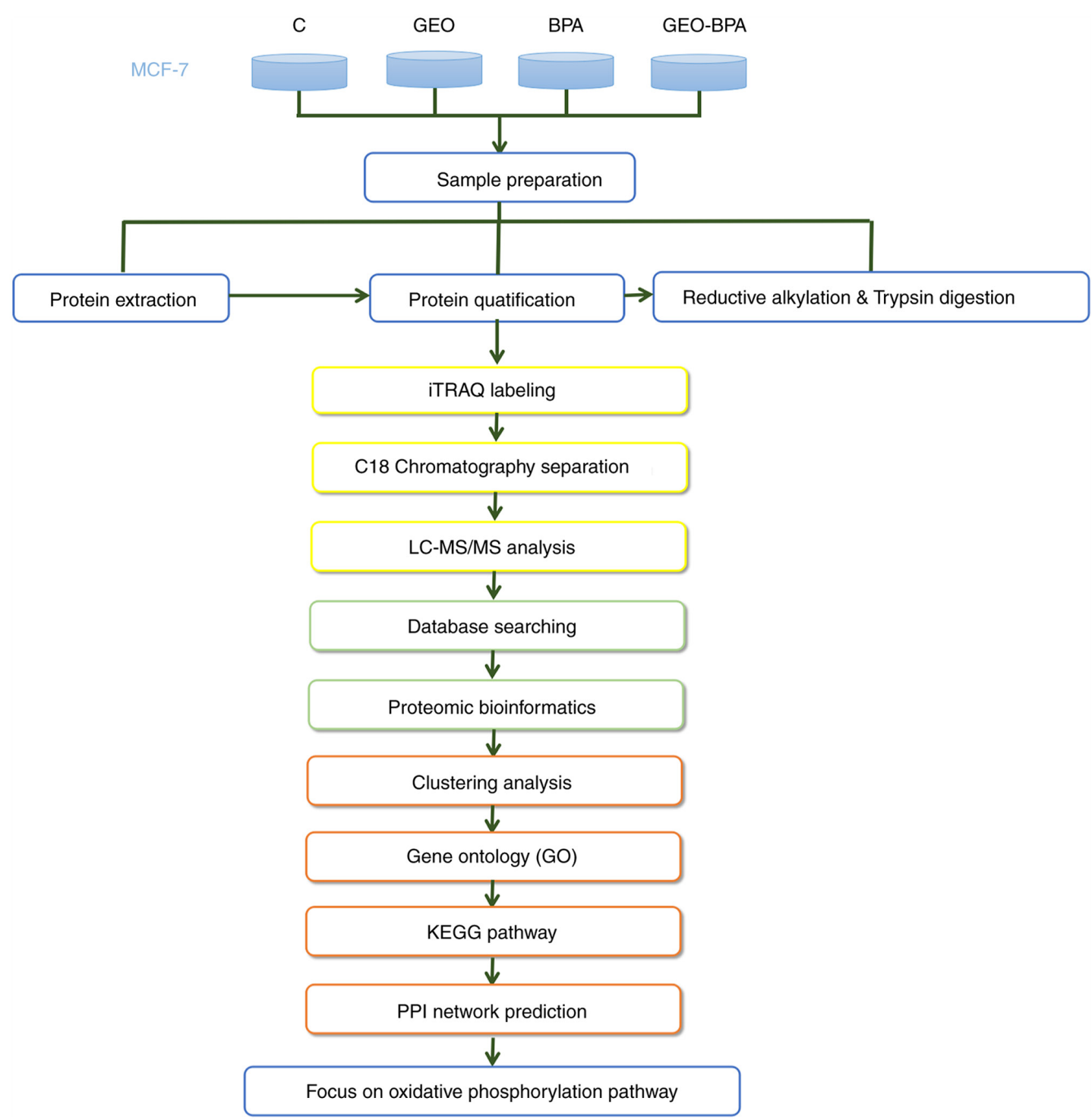

Figure 2. Experimental process. For quantitative proteomic analysis of design of exper-iment, the experiment was divided into four groups (control, GEO, BPA and GEO-BPA), and each experiment was performed in triplicate. The extracted proteins were prepared by reductive alkylation, digested with trypsin and labeled with Iraqi reagents. Analysis was performed using reversed-phase LC-MS/MS. Bioinformatics tools were further used to analyze the resulting data. GEO, ginger essential oil; BPA, bisphenol A; LC, liquid chromatography; MS, mass spectrometry; KEGG, Kyoto Encyclopedia of Genes and Genomes; PPI, protein-protein interaction.

Compared with the control group, MCF-7 cells treated with GEO, BPA and GEO-BPA showed 45 (14 up- and 31 downregulated) and 481 (141 up- and 340 downregulated) differentially expressed proteins. Compared with the BPA group, MCF-7 cells treated with GEO-BPA showed 210 (117 up- and 93 downregulated) differentially expressed proteins, respectively (Tables I 
Table I. Protein quantification in MCF-7 cells treated with GEO or BPA alone and GEO-BPA combined.

\begin{tabular}{lcrr}
\hline Comparison between groups & Upregulated proteins, $\mathrm{n}$ & Downregulated pro-teins, $\mathrm{n}$ & Protein count, $\mathrm{n}$ \\
\hline GEO vs. C & 14 & 31 & 45 \\
BPA vs. C & 141 & 340 & 481 \\
GEO-BPA vs. C & 13 & 21 & 34 \\
GEO-BPA vs. BPA & 117 & 93 & 210 \\
\hline
\end{tabular}

GEO, ginger essential oil; BPA, bisphenol A; C, control.

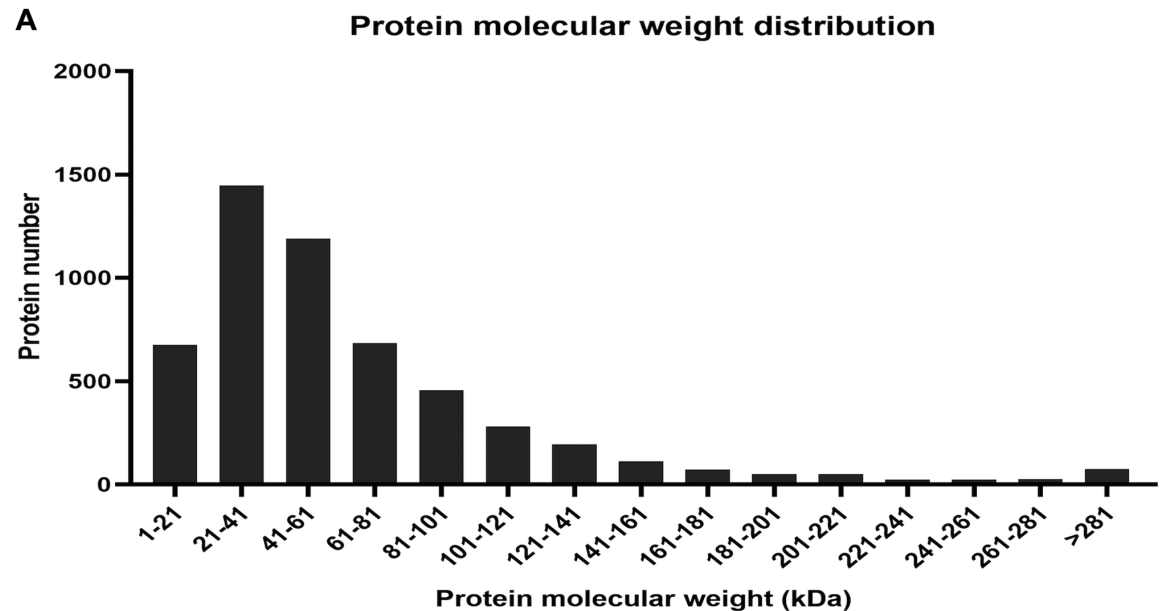

B

Peptide length distribution

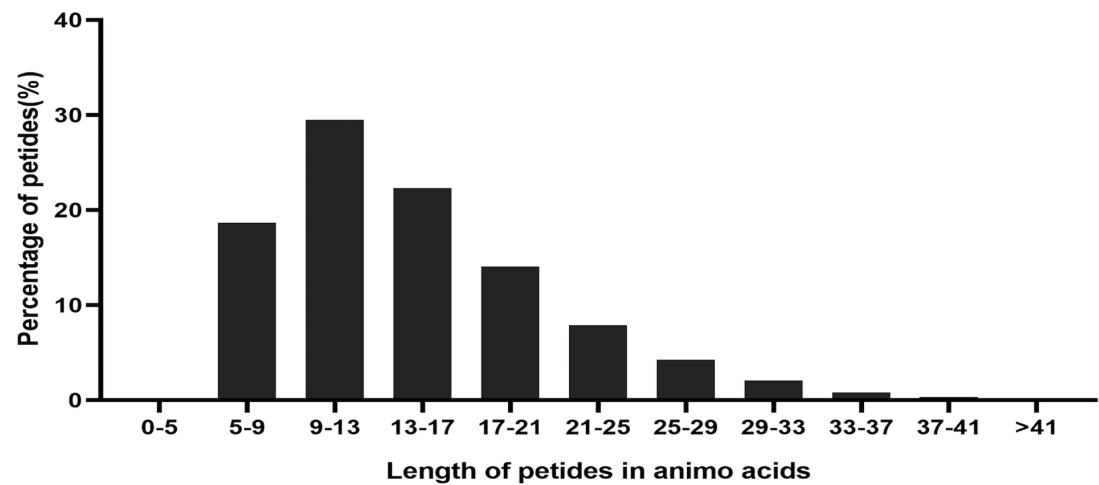

Figure 3. Quality control of protein data validation. (A) Protein mass distribution of all identified proteins. (B) Protein length distribution of all identified peptides.

and SII-IV). According to the optimal selection criterion for differentially expressed proteins, compared with cells treated with BPA alone, some proteins in cells treated with GEO and BPA were significantly upregulated or downregulated $(\mathrm{P}<0.05)$. According to the aforementioned criteria, a total of 34 differentially expressed proteins were further processed (Table II), of which 13 were significantly upregulated and 21 were significantly downregulated $(\mathrm{P}<0.05)$.

Clustering analysis. The results of hierarchical clustering are displayed in the form of a heat map, in which red indicates upregulation and blue indicates downregulation. The observed difference in protein expression between the groups are shown in Fig. 4. It was observed the overall expression pattern of genes in the GEO, BPA and GEO-BPA groups was different compared with those in the control group. In the control group, most genes showed a highly upregulated expression patterns (red bands), while in the GEO and GEO-BPA groups, most genes were downregulated.

GO function annotation and analysis. GO is a type of functional classification system. The GO database provides a standardized description of gene products from the per-spectives of function, participating in biological pathways and localization in cells. The GO database showed 53, 59 and 57 functional annotations for differentially expressed 


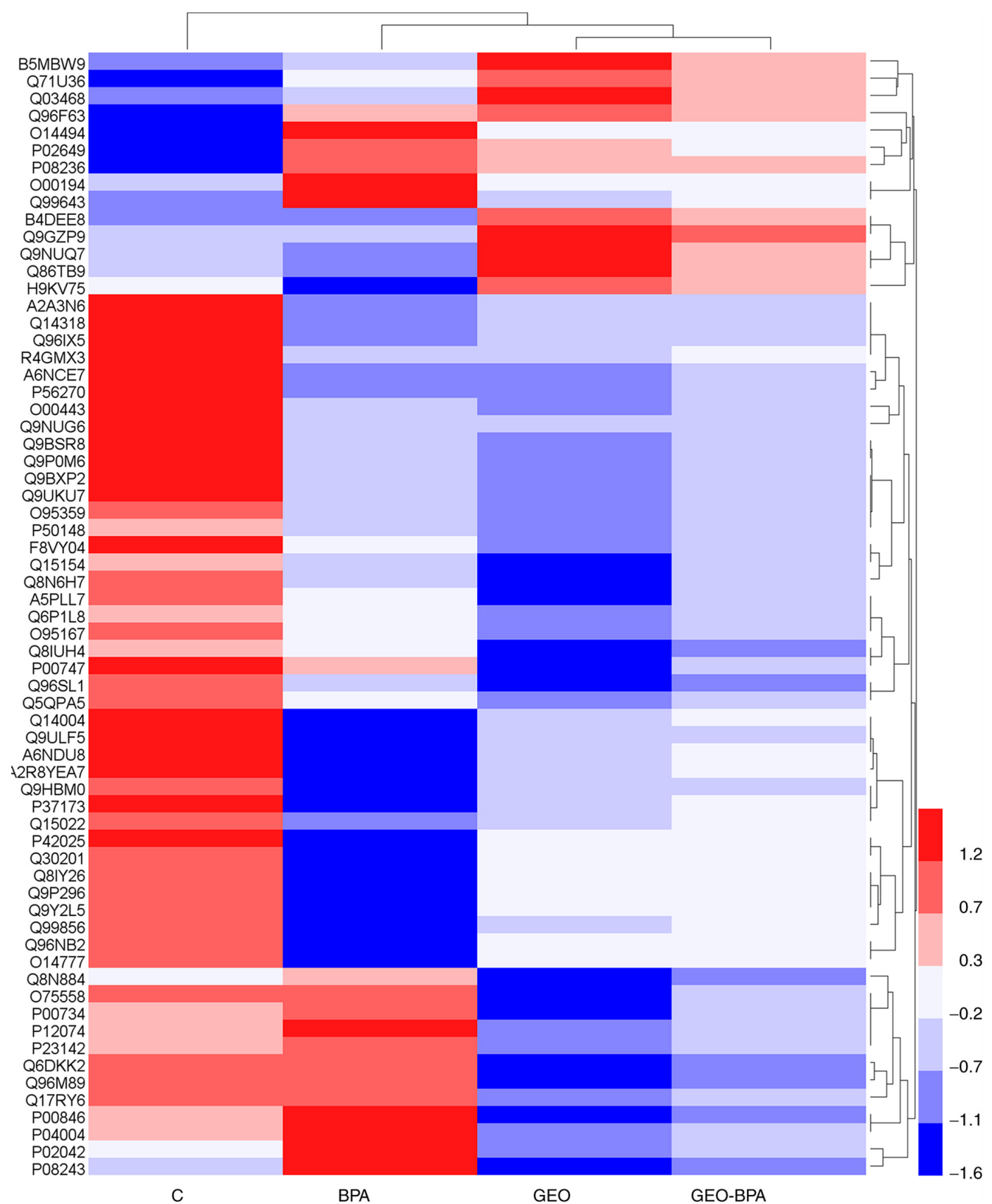

Figure 4. Cluster analysis of differentially expressed proteins between GEO-BPA and the control. Color changes with the expression of the protein, and blue colors indicate negative correlation, red colors indicates positive correlation, the more intense the color, the strongest the correlation. GEO, ginger essential oil; BPA, bisphenol A.

proteins in cells treated with GEO $(n=45)$, BPA $(n=481)$ and GEO-BPA $(n=210)$ (Tables SV-SVII). In addition, the GO functional annotations of differentially expressed proteins in each group were analyzed. The results showed that compared with the con-trol group, 45 differentially expressed proteins were more likely to be located at the cell parts and macromolecular complex in GEO alone group, and were closely associated with catalytic activity and protein binding activity. These proteins are involved in cellu-lar and metabolic processes and responses to stimuli (Fig. 5). Only 111 diffeentially expressed proteins in the BPA alone group were reported in the organelles and membrane, which were associated with structural and molecular activity. These proteins were involved in various biological processes, such as metabolic processes, organiza-tion of cellular component or biogenesis and localization (Fig. 6). The 192 differentially expressed proteins in the GEO-BPA combination group were primarily located in the cell part, single-organism process, organelle part and were involved in catalytic activity and structural molecule activity, which could affect signaling, cellular component organ-ization or biogenesis and negative regulation of biological processes (Fig. 7). Changes in biological processes indicated that GEO affects BPA-treated breast cancer cells

KEGG pathway analysis. The KEGG database can be used to associate the gene catalogue in the whole genomes with higher levels of system function at the cell, species and ecosystem levels (24). Through KEGG pathway analysis, the 
GO annotations analysis (level 2) $\quad$ Biological_process

- Molecular_function

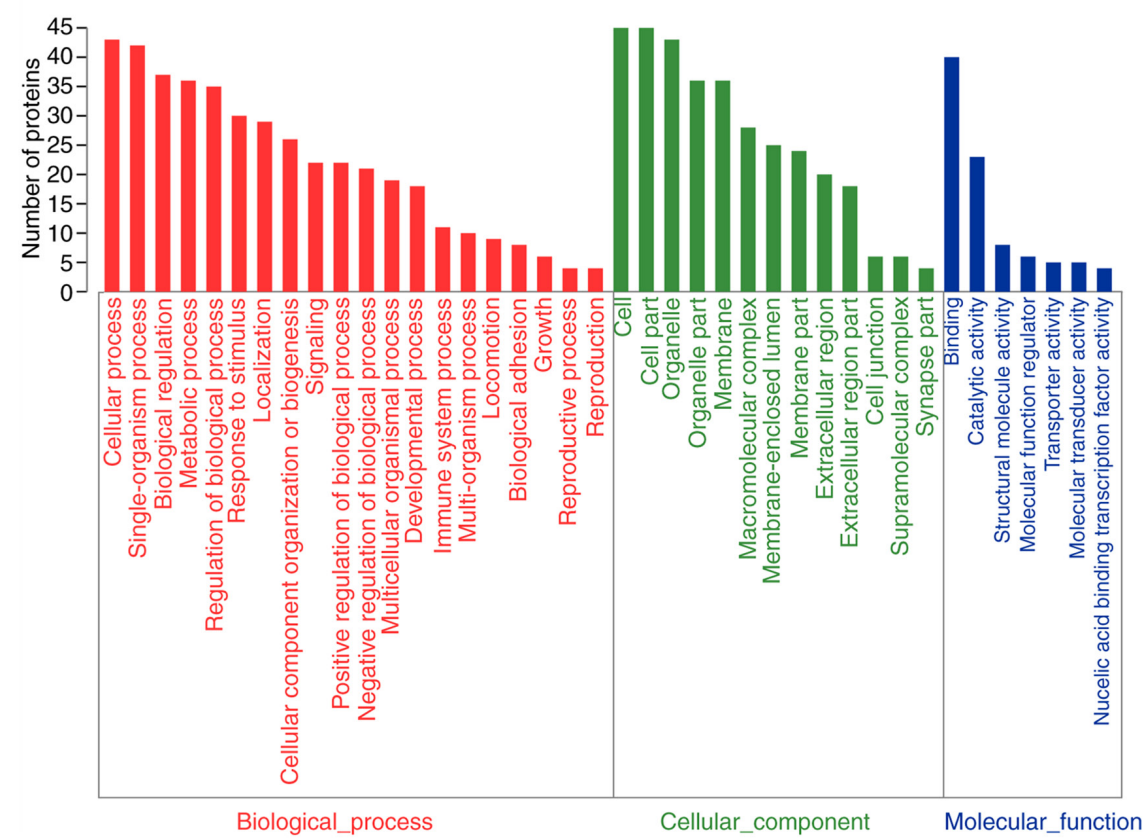

Figure 5. MCF-7 cells perform GO analysis of the protein function of GEO. Compared with the control group, there were 17 differentially expressed proteins in the GEO treatment group. GO function analysis of 17 differentially expressed proteins were divided into biological process, molecular function and cellular component. GO, Gene Ontology; GEO, ginger essential oil.

GO annotations analysis (level 2)

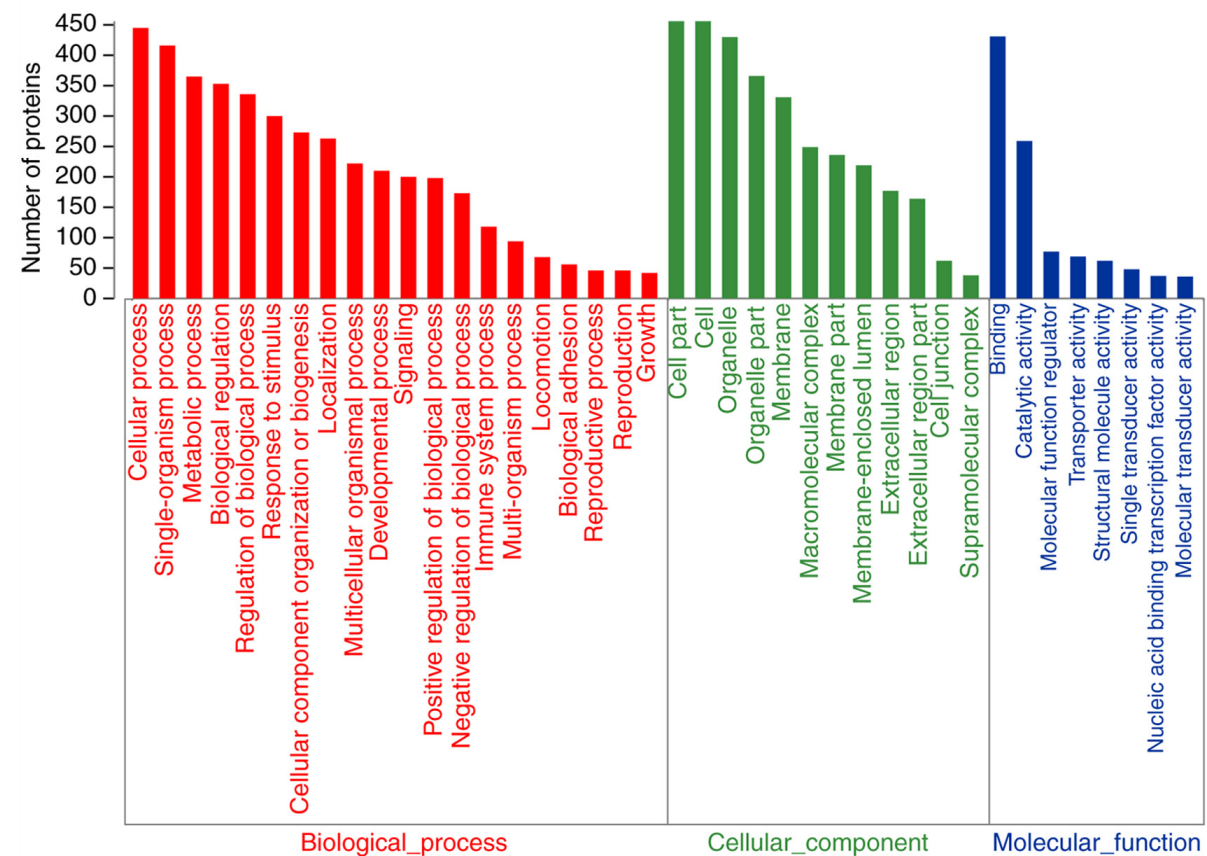

Figure 6. MCF-7 cells perform GO analysis of the protein function of BPA. Compared with the control group, there were 111 differentially expressed proteins in the BPA treatment group. GO function analysis of 111 differentially expressed proteins were divided into biological process, molecular function and cellular component. GO, Gene Ontology; BPA, bisphenol A.

key signaling path-ways and related regulatory processes of each group were obtained (Tables SVIII-SX). The KEGG secondary category of each group is presented in Figs. 8-10.
KEGG analy-sis showed that the signaling pathways identified in the GEO group were primarily associated with energy metabolism, transportation and catabolism, immune system 
GO annotations analysis (level 2) $\quad$ Biological_process

Mollular_componen

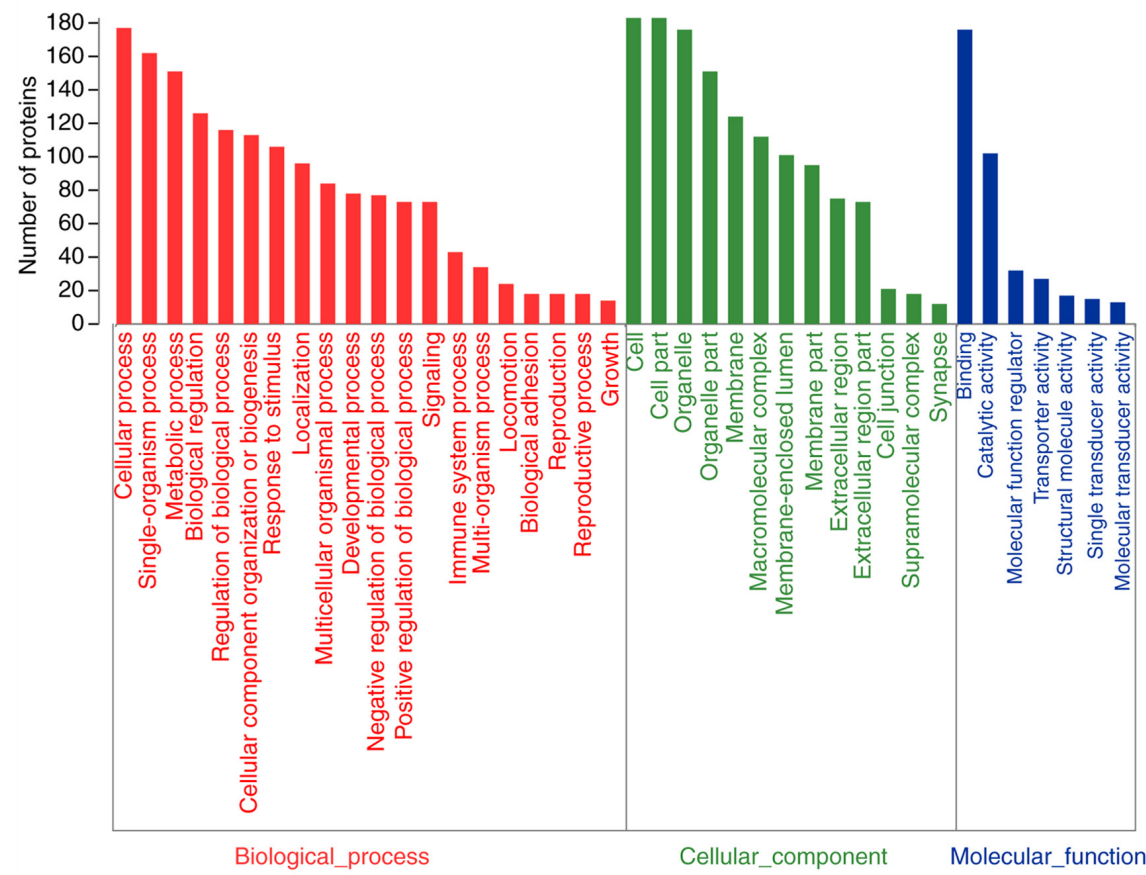

Figure 7. MCF-7 cells perform GO analysis of the protein function of GEO-BPA. Compared with the BPA group, there were 128 differentially expressed proteins in the GEO-BPA treatment group. GO function analysis of 128 differentially expressed proteins were divided into biological process, molecular function, and cellular component. Gene Ontology; GEO, ginger essential oil; BPA, bisphenol A.

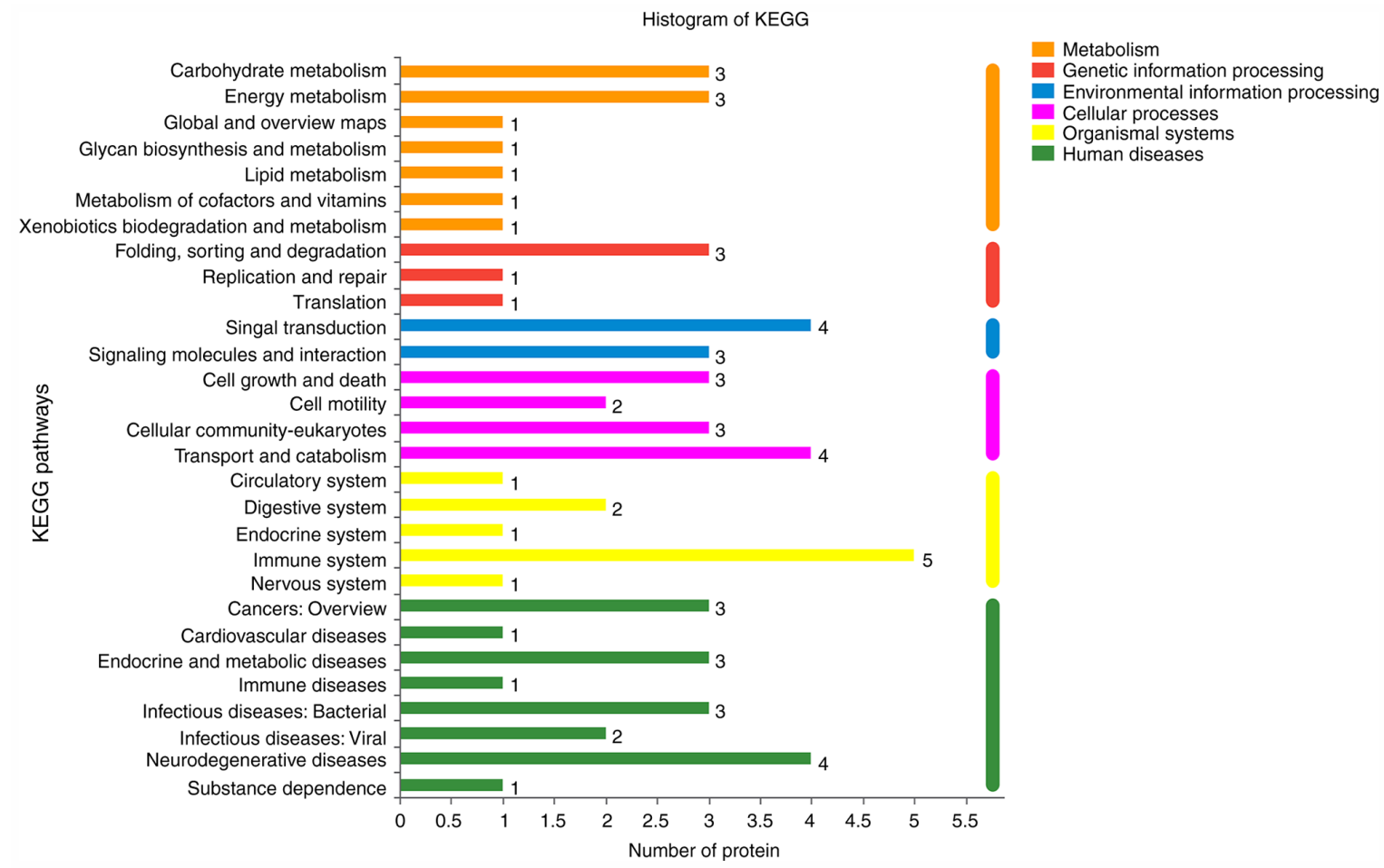

Figure 8. KEGG analyses of protein functions in GEO-treated MCF-7 cells. Compared with the control group, 17 differentially expressed proteins in the GEO treatment group were annotated using the KEGG database. KEGG, Kyoto Encyclopedia of Genes and Genomes; GEO, ginger essential oil.

and cell motility (Fig. 8). KEGG signaling pathways in the BPA group were mainly associated with the oncogenes signaling pathway, cellular community-eukaryotes and the endocrine system (Fig. 9). The KEGG signaling pathway in the GEO-BPA combination group was associated with signal transduction, immune system, energy metabolism, cancer and endocrine and metabolic diseases (Fig. 10), and from the description of the pathway, it can be seen that the main 


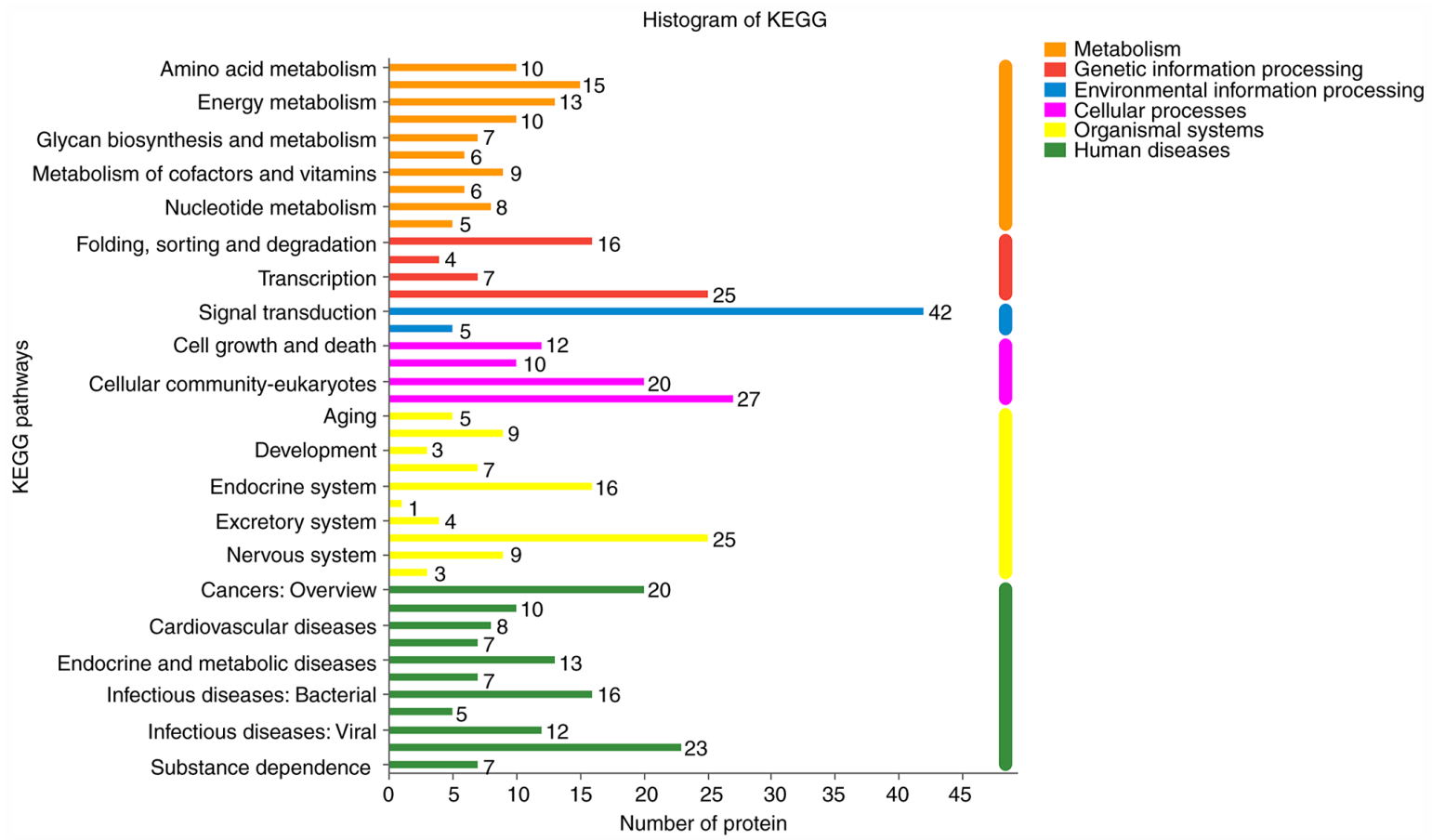

Figure 9. KEGG analyses of protein functions in BPA-treated MCF-7 cells. Compared with the control group, 111 diffeentially expressed proteins in the BPA treatment group were annotated using the KEGG database. KEGG, Kyoto Encyclopedia of Genes and Genomes; BPA, bisphenol A.

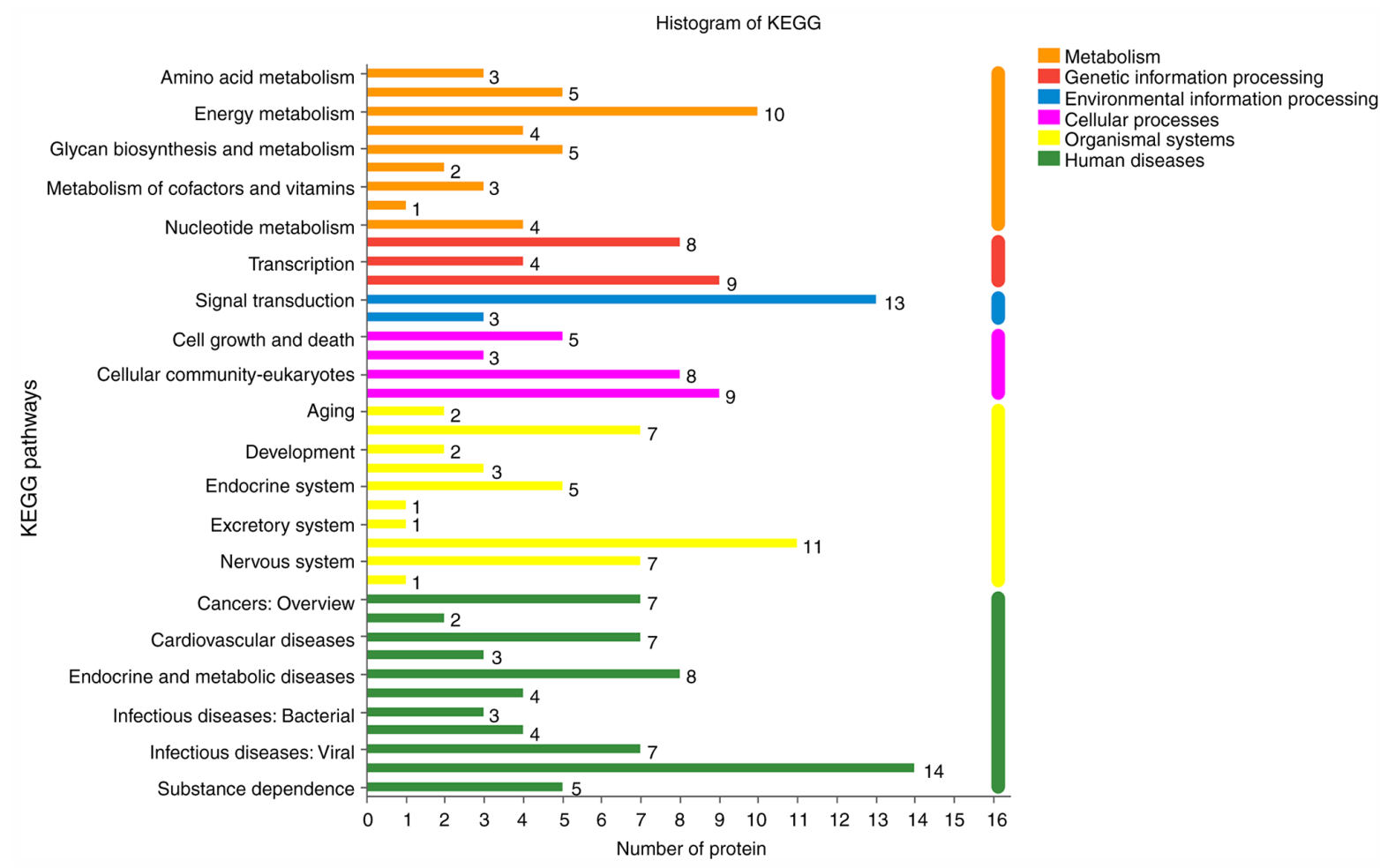

Figure 10. Compared with the BPA group, 128 differentially expressed proteins in the GEO-BPA combined treatment group was annotated using the KEGG database. KEGG, Kyoto Encyclopedia of Genes and Genomes; BPA, bisphenol A; GEO, ginger essential oil.

pathways of these three groups are associated with oxidative phosphorylation, endocytosis, focal adhesions and ribosomes (Tables SVIII-SX; Fig. 10).

PPI network analysis. Differentially expressed proteins between direct interaction mod-els may help in gaining important information about the target protein (25). Analysis of PPI network is shown in Fig. 11, the yellow represents the protein with highest degree value, while other colors represent other proteins that interact with these differentially expressed target proteins. The PPI analysis revealed the connection degree of the pro-tein interactions. A higher degree of connectivity may show 


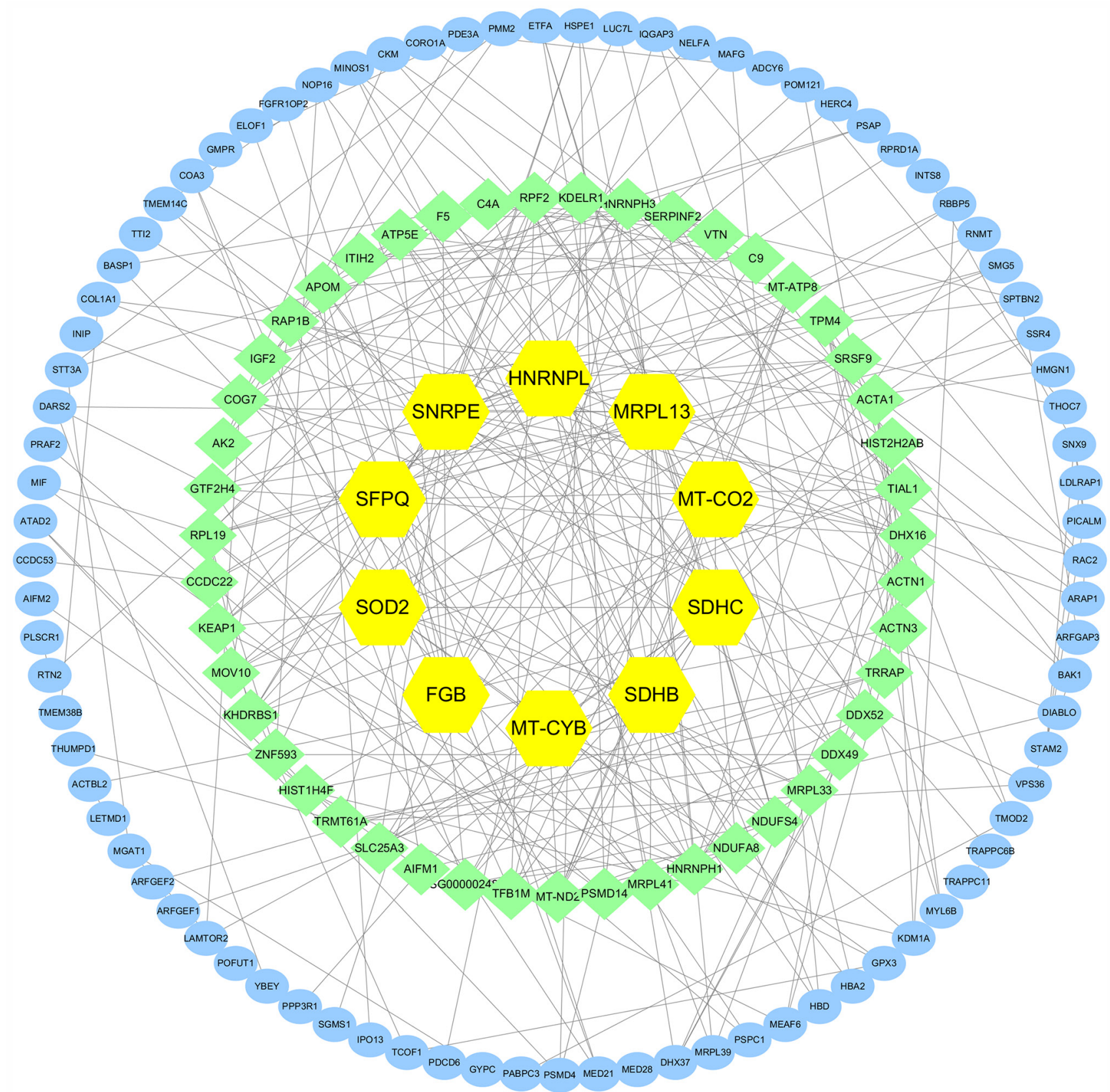

Figure 11. Ginger essential oil and bisphenol A-treated MCF-7 cells protein-protein interaction analysis. The degree value increases from yellow to green, and then to blue. The top ten with degree values in GEO-BPA group are marked yellow: SNRPE, SDHB, SDHC, MRPL13, SOD2, FGB, HNRNPL, MT-CO2, MT-CYB And SFPQ. yellow and green markers are other differential proteins.

more protein complexes. SNRPE, SDHB, SDHC, MRPL13, SOD2, MT-CYB, MT-CO2, HNRNPL, SFPQ and FGB showed a high degree of connectivity by comparing the differentially expressed proteins between GEO-BPA and BPA treatments and these targets marked as yellow. The middle-degree targets such as NDUFA 8, NDUFA 4, ND 2 and IGF 2 are marked in light green, and blue marked targets with low degree values.

\section{Discussion}

iTRAQ is one of the most advanced technologies in modern quantitative proteomics (26). It combines stable isotope labeling and tandem mass spectrometry, and can compare the relative content of protein in normal and diseased samples in one experiment (27). The present study systematically identified and analyzed the differences of proteome expression in breast cancer cells treated with GEO-BPA and BPA alone. The re-sults showed that GEO effectively inhibited the viability of breast cancer cells, which is in accordance with the findings of Karkihave, GEO inhibits CD44/ALDH1, the hall-marks of breast cancer cells (17), and BPA promoted the proliferation of MCF-7 cells, which is consistent with previous research (28). The GEO-BPA, BPA and GEO treat-ment groups showed 34, 481 and 210 differentially expressed proteins, respectively, compared with the control group. These differentially expressed proteins could be used as biomarkers to evaluate the effect of GEO on breast cancer induced by BPA, and to guide future treatment strategies for breast cancer. 
Through GO annotation and KEGG pathway analysis, the specific regulation function and signal transduction pathways during GEO-BPA treatment were determined, which provided new insights into breast cancer development and proposed potential treatment strategies. GO functional annotations showed that, compared with the control group, 210 proteins were differentially expressed in the GEO-BPA combined treatment group. These differentially expressed proteins were mainly located in organelles and membranes, which can affect signal transduction, tissue or biogenesis of cellular com-ponents and negative regulation of biological processes. KEGG signal pathway analysis showed that oxidative phosphorylation, cAMP signaling pathway, focal adhesions and ribosomes in the GEO-BPA combination treatment group was richer compared with other pathways. The oxidative phosphorylation pathway contains the largest number of differential proteins, which is related to energy metabolism and is the key to regulating the content of ATP and oxygen in cells (29).

Tumor cells obtain energy through the glycolysis and oxidative phosphorylation pathways. Under normoxic conditions, normally differentiated cells obtain energy primarily through oxidative phosphorylation, which is generally $\geq 40 \%$ of the total ATP. However, cancer cells tend to rely on aerobic glycolysis (a phenomenon of converting glucose into lactic acid under aerobic conditions) to generate energy, and use the inter-mediate products of glycolysis as building blocks of cell proliferation (30). The dysregulation of mitochondrial metabolism is a characteristic of the metabolic reprogramming of cancer cells (31). However, aerobic glycolysis is not enough to completely replace the energy produced by oxidative phosphorylation (32). Even in an anoxic environment, continuous mitochondrial oxidative phosphorylation is still indispensable for the biological activities of tumor cells. In recent years, research on the antitumor effect of energy metabolism pathways has become increasingly popular $(33,34)$. Sharma and Singh reported that dichloroacetate can stimulate oxidative phosphorylation by changing mitochondrial morphology for glycolysis, inducing apoptosis and inhibiting proliferation of breast cancer cells (33). Fan et al (34) reported that Jar-TA, a natural diterpenoid deriva-tive, induces apoptosis of esophageal cancer cells by double inhibition of glycolysis/oxidative phosphorylation.

KEGG analysis showed that there were 10 differentially expressed proteins in the GEO-BPA combined treatment group, which regulated the oxidative phosphorylation pathway and possibly regulated intracellular energy metabolism and oxygen transport in breast cells. Meanwhile, the top five degrees of PPI network interaction results were SNRPE, SDHB, SDHC, MRPL13 and SOD2, among which SDHB, SDHC and SOD2 were associated with energy metabolism (35). The present study showed that down-regulation of the protein of SDHB, SDHC, SOD2 and COX-2 may be an important factor related to oxidative damage that promotes GEO to treat BPA-induced breast cancer cells. SDH is a key enzyme in the tricarboxylic acid cycle and oxidative phosphorylation of the respiratory chain. The lack of SDH inhibits the tricarboxylic acid cycle and the transmission of electrons in the respiratory chain, resulting in the production of ROS and oxidative damage to cells. Therefore, whether the functions of the SDHB and SDHC genes are normal or not will affect the function of SDH, which will eventually lead to excessive production of ROS in mitochondria and induce apoptosis (35). Functional studies of yeast models have shown that deletion of the SDHA or SDHB genes and point mutations of SDHB, SDHC and SDHD are associated with SDH dysfunction and increased production of ROS (36). In human cell lines, SDHB-silencing, drug inhibition or RNA interference also eliminates the activity of complex II, and increases production of ROS and nuclear stability of HIF1 $\alpha$ under normoxic conditions (37). Compared with parent cells, SDHC mutations also increase the level of ROS production, genomic instability and tumorigenesis of mutant cells (38). The present study also demonstrated that the expression of SOD2 protein was downregulated. SOD2 is a type of superoxide dismutase, which catalyzes the conversion of superoxide to oxygen and hydrogen peroxide through a disproportionate reaction, thus removing superoxide and protecting cells from oxidative damage (39). SOD2-downregulation in the present study indicated that there may have been an oxidative stress reaction, releas-ing peroxide and inducing cell death.

The current results demonstrated that the expression of COX-2 protein was de-creased in the GEO-BPA treatment group, which is consistent with the results of previous studies. For example, Han et al showed that downregulation of COX-2 can make survivin and Bcl-2 mRNA and protein expression levels decrease, Bax mRNA and pro-tein expression levels increase, thus affect proliferation and apoptosis of human breast cancer MCF-7 cells (40). Meanwhile, malonate and 3-nitropropionic acid are com-pounds that specifically inhibit SDH activity and then induce ROS production and apoptosis (41). However, as anticancer drugs, both of these compounds have secondary toxicity (neurological diseases), so their value for in vivo treatment is limited (42). Therefore, the active ingredients of traditional Chinese medicine that are used for medi-cine and food are worthy of in-depth study. Besides, decreased expression of enzymes involved in oxidative phosphorylation, including NADH dehydrogenase (ubiquinone) $1 \beta$ subcomplex subunit 8 (NDUFA8), NADH dehydrogenase (ubiquinone) iron-sulfur protein 4 (NDUFS4) and NADH dehydrogenase 2 (ND2), may cause mitochondrial defects and affect the energy metabolism of breast cancer cells (43).

Overall, the iTRAQ-based proteomics data presented in the current study may be useful to clarify the proteomics profile of MCF-7 cells treated with GEO and BPA, and these data may help improve our understanding of the molecular mechanisms underly-ing the effects of these treatments. It was reported that, in MCF-7 cells treated with GEO-BPA, seven differentially expressed proteins were associated with oxidative phosphorylation (COX-2, NDUFA8, NDUFS4, ND2, SDHB, SDHC and SOD2) were significantly reduced $(\mathrm{P}<0.05)$. KEGG analysis highlighted that oxidative phos-phorylation may be one of the mechanisms by which GEO inhibited BPA-induced MCF-7 breast cancer cell proliferation. PPI analysis showed that SNRPE, SDHB, SDHC, MRPL13 and SOD2 had high connectivity and were in the center of the network. These differentially expressed proteins may be the key to the inhibitory effect of GEO on BPA-induced MCF-7 cells and showed that the molecular function about energy metabolism underlying this effect. The limitation of the present study lies in screening differentially expressed proteins through in vitro 
experiments. In future research, in vivo and in vitro experiments must be used to further analyze the role and mechanisms of ginger against breast cancer.

\section{Acknowledgements}

Not applicable.

\section{Funding}

The present study was supported by The Double-First Class Discipline Construction Project (grant nos. JXSYLXK-ZHYAO115 and ZHYI025) and The Program of Health Commission Jiangxi Province (grant nos. 20195635 and 2019A262).

\section{Availability of data and materials}

The datasets used and/or analyzed during the present study are available from the corresponding author upon reasonable request.

\section{Authors' contributions}

DL, TH and ZL carried out the experiments and drafted the manuscript. DL and LL participated in the statistical analyses. LC, XL and QW conceived and designed the study and helped to draft the manuscript. All authors have read and approved the final manuscript.

\section{Ethics approval and consent to participate}

Not applicable.

\section{Patient consent for publication}

Not applicable.

\section{Competing interests}

The authors declare that they have no competing interests.

\section{References}

1. Bray F, Ferlay J, Soerjomataram I, Siegel RL, Torre LA and Jemal A: Global cancer statistics 2018: GLOBOCAN estimates of incidence and mortality worldwide for 36 cancers in 185 countries. CA Cancer J Clin 68: 394-424, 2018.

2. Derouiche S, Warnier M, Mariot P, GossetP, Mauroy B, Bonnal JL, Slomianny C, Delcourt P, Prevarskaya N and Roudbaraki M: Bisphenol A stimulates human prostate cancer cell migration via remodelling of calcium signalling. Springerplus 2: 54, 2013.

3. Kloukos D, Pandis $\mathrm{N}$ and Eliades T: In vivo bisphenol - a release from dental pit and fissure sealants: A systematic review. J Dent 41: 659-667, 2013

4. Krishnan AV, Stathis P, Permuth SF, Tokes L and Feldman D: Bisphenol-A: An estrogenic substance is released from polycarbonate flasks during autoclaving. Endocrinology 132: 2279-2286, 1993.

5. Huang YQ, Wong CK, Zheng JS, Bouwman H, Barra R, Wahlström B, Neretin L and Wong MH: Bisphenol A (BPA) in China: A review of sources, environmental levels, and potential human health impacts. Environ Int 42: 91-99, 2012.

6. Rogers JA, Metz L and Yong VW: Review: Endocrine disrupting chemicals and immune responses: a focus on bisphenol-A and its potential mechanisms. Mol Immunol 53: 421-430, 2013.
7. Vom Saal FS, Nagel SC, Coe BL, Angle BM and Taylor JA: The estrogenic endocrine disrupting chemical bisphenol A (BPA) and obesity. Mol Cell Endocrinol 354: 74-84, 2012.

8. Lui YZ, Zeng GQ, Ge LC, Liu H, Du J and Wang HS: Bisphenol A induces epithelial mesenchymalization of human breast cancer MCF-7 cells. Acta Scientiae Circumstantiae 35: 608-612, 2015 (In Chinese).

9. White B: Ginger: An overview. Am Fam Physician 75: 1689-1691, 2007.

10. Ali BH, Blunden G, Tanira MO and Nemmar A: Some phytochemical, pharmacological and toxicological properties of ginger (Zingiber officinale Roscoe): A review of recent research. Food Chem Toxicol 46: 409-420, 2008.

11. Ishiguro K, Ando T, Maeda O, Ohmiya N, Niwa Y, Kadomatsu K and Goto $\mathrm{H}$ : Ginger ingredients reduce viability of gastric cancer cells via distinct mechanisms. Biochem Biophys Res Commun 362: 218-223, 2007.

12. Jeong C-H, Bode AM, Pugliese A, Cho YY, Kim HG, Shim JH, Jeon YJ, Li H, Jiang H and Dong Z: [6]-Gingerol suppresses colon cancer growth by targeting leukotriene A4 hydrolase. Cancer Res 69: 5584-5591, 2009.

13. Surh YJ, Park KK, Chun KS, Lee LJ, Lee E and Lee SS: Anti-tumor-promoting activities of selected pungent phenolic substances present in ginger. J Environ Pathol Toxicol Oncol 18: 131-139, 1999.

14. Brahmbhatt M, Gundala SR, Asif G, Shamsi SA and Aneja R: Ginger phytochemicals exhibit synergy to inhibit prostate cancer cell proliferation. Nutr Cancer 65: 263-272, 2013.

15. Santos PA.SR, Avanço GB, Nerilo SB, Marcelino RIA, V. Janeiro V, Valadares MC and Machinski M: Assessment of Cytotoxic Activity of Rosemary (Rosmarinus officinalis L.), Turmeric (Curcuma longa L.), and Ginger (Zingiber officinale R.) Essential Oils in Cervical Cancer Cells (HeLa). ScientificWorldJournal 2016: 9273078, 2016.

16. Prasad S and Tyagi AK: Ginger and its constituents: role in prevention and treatment of gastrointestinal cancer. Gastroenterol Res Pract 2015: 142979, 2015.

17. Karki N: Inhibitory activity of ginger oil against breast cancer cells (2011). LSU Master's Theses. 1714. https://digitalcommons. lsu.edu/gradschool_theses/1714.

18. Brooks SC, Locke ER and Soule HD: Estrogen receptor in a human cell line ( MCF-7) from breast carcinoma. J Biol Chem 248: 6251-6253, 1973 .

19. Ninth Chinese Pharmacopoeia Commission: Pharmacopoeia of the People's Republic of China (1) China Medical Science and Technology Press, China, pp 93, 2010.

20. Kan Y, Lyu Q, Jiang N, Han S, Li J, Burdman S and Luo L: iTRAQ-based proteomic analyses of the plant-pathogenic bacterium Acidovorax citrulli during entrance into and resuscitation from the viable but nonculturable state. J Proteomics 211: 103547, 2020.

21. Gao Z, Wang J, Bai Y, Bao J and Dal E: Identification and Verification of the Main Differentially Expressed Proteins in Gastric Cancer via iTRAQ Combined with Liquid Chromatography-Mass Spectrometry. Anal Cell Pathol 2019: 5310684, 2019.

22. Szklarczyk D, Gable AL, Lyon D, Junge A, Wyder S, Huerta-Cepas J, Simonovic M, Doncheva NT, Morris JH, Bork P, et al: STRING v11: Protein-protein association networks with increased coverage, supporting functional discovery in genome-wide experimental datasets. Nucleic Acids Res 47D: D607-D613, 2019.

23. Swaney DL, Wenger CD and Coon JJ: Value of using multiple proteases for large-scale mass spectrometry-based proteomics. J Proteome Res 9: 1323-1329, 2010.

24. Kanehisa M and Goto S: KEGG: Kyoto encyclopedia of genes and genomes. Nucleic Acids Res 28: 27-30, 2000.

25. Yu LR, Zeng R, Shao XX, Wang N, Xu YH and Xia QC: Identification of differentially expressed proteins between human hepatoma and normal liver cell lines by two-dimensional electrophoresis and liquid chromatography-ion trap mass spectrometry. Electrophoresis 21: 3058-3068, 2000.

26. Unwin RD, Griffiths JR and Whetton AD: Simultaneous analysis of relative protein expression levels across multiple samples using iTRAQ isobaric tags with 2D nano LC-MS/MS. Nat Protoc 5: 1574-1582, 2010

27. Jamaluddin MFB, Nagendra PB, Nahar P, Oldmeadow C and Tanwar PS: Proteomic Analysis Identifies Tenascin-C Expression Is Upregulated in Uterine Fibroids. Reprod Sci 26: 476-486, 2019.

28. Feifei S and Yinyin W: Research status and progress of relationship between environmental bisphenol $\mathrm{A}$ and reproductive system malignant tumors. Health Res 38: 532-537, 2018. 
29. Lui Q, Hu LG, Zhou QF and Jiang GB: Tetrabromobisphenol A bis(2-hydroxyethylether) induced dysfunction of respiratory chain oxidative phosphorylation and energy metabolism rat pheochromocytoma cells by high performance liquid chromatography-electrospray ionization-tandem mass spectrometry. Chinese J Chromatography 35: 1-7, 2017.

30. Li QX, Zhang P, and Liu H: Characteristics and progress of energy metabolism of tumor cells. Chinese Pharmacological Bulletin 33, 1499-1502, 2017.

31. Liberti MV and Locasale JW: The Warburg Effect: How Does it Benefit Cancer Cells? Trends Biochem Sci 41: 287, 2016.

32. Jose C, Bellance N and Rossignol R: Choosing between glycolysis and oxidative phosphorylation: A tumor's dilemma? Biochim Biophys Acta 1807: 552-561, 2011.

33. Sharma P and Singh S: Combinatorial Effect of DCA and Let-7a on Triple-Negative MDA-MB-231 Cells: A Metabolic Approach of Treatment. Integr Cancer Ther 19: 1534735420911437, 2020.

34. Fan XX, Su N, Huang XJ, Li YF, Jia A, Fan JP, Wang AF, Zhao NM and Ma YC: Jar-TTA, a natural diterpenoid derivatives, induces apoptosis in human esophageal cancer cells through dual inhibition of glycolysis and oxidative phosphorylation. Chinese Pharmacological Bulletin 35, 950-957, 2019.

35. Guzy RD, Sharma B, Bell E, Chandel NS and Schumacker PT: Loss of the SdhB, but Not the SdhA, subunit of complex II triggers reactive oxygen species-dependent hypoxia-inducible factor activation and tumorigenesis. Mol Cell Biol 28: 718-731, 2008.

36. Goffrini P, Ercolino T, Panizza E, Giachè V, Cavone L, Chiarugi A, Dima V, Ferrero I and Mannelli M: Functional study in a yeast model of a novel succinate dehydrogenase subunit $\mathrm{B}$ gene germline missense mutation (C191Y) diagnosed in a patient af-fected by a glomus tumor. Hum Mol Genet 18: 1860-1868, 2009.

37. Guzy RD, Sharma B, Bell E, Chandel NS and Schumacker PT: Loss of the SdhB, but Not the SdhA, subunit of complex II triggers reactive oxygen species-dependent hypoxia-inducible factor activation and tumorigenesis. Mol Cell Biol 28: 718-731, 2008 .
38. Slane BG, Aykin-Burns N, Smith BJ, Kalen AL, Goswami PC, Domann FE and Spitz DR: Mutation of succinate dehydrogenase subunit $\mathrm{C}$ results in increased $\mathrm{O}_{2}$, oxidative stress, and genomic instability. Cancer Res 66: 7615-7620, 2006.

39. Zelko IN, Mariani TJ and Folz RJ: Superoxide dismutase multigene family: A comparison of the CuZn-SOD (SOD1), Mn-SOD (SOD2), and EC-SOD (SOD3) gene structures, evolution, and expression. Free Radic Biol Med 33: 337-349, 2002.

40. Han H, Yang S, Lin SG, Xu CS and Han ZH: Effects and mechanism of downregula-tion of COX 2 expression by RNA interference on proliferation and apoptosis of hu-man breast cancer MCF 7 cells. Mol Med Rep 10: 3092-3098, 2014.

41. Gomez-Lazaro M, Galindo MF, Melero-Fernandez de Mera RM, Fernandez-Gómez FJ, Concannon CG, Segura MF, Comella JX, Prehn JH and Jordan J: Reactive oxygen species and p38 mitogen-activated protein kinase activate Bax to induce mito-chondrial cytochrome $c$ release and apoptosis in response to malonate. Mol Pharmacol 71: 736-743, 2007.

42. Liot G, Bossy B, Lubitz S, Kushnareva Y, Sejbuk N and Bossy-Wetzel E: Com plex II inhibition by 3-NP causes mitochondrial fragmentation and neuronal cell death via an NMDA- and ROS-dependent pathway. Cell Death Differ 16: 899-909, 2009.

43. Balsa E, Marco R, Perales-Clemente E, Szklarczyk R, Calvo E, Landázuri MO and Enríquez JA: NDUFA4 is a subunit of complex IV of the mammalian electron transport chain. Cell Metab 16: 378-386, 2012.

This work is licensed under a Creative Commons Attribution-NonCommercial-NoDerivatives 4.0 International (CC BY-NC-ND 4.0) License. 